\title{
EXPLORING POLICE USE OF FORCE DECISION- MAKING PROCESSES AND IMPAIRMENTS USING A NATURALISTIC DECISION-MAKING APPROACH
}

\author{
KELLY A. HINE \\ The Australian National University \\ LOUISE E. PORTER \\ NINA J. WESTERA \\ Griffith University \\ GEOFFREY P. ALPERT \\ University of South Carolina \\ ANDREA ALLEN \\ Clayton State University
}

\begin{abstract}
As part of their duties, police regularly engage with citizens, which can result in the use of force. While we know how often and under what circumstances officers use force, little is known about officers' decision-making processes that lead to force. The study took a naturalistic decision-making approach to analyze debrief sessions between 91 recruits and their trainers after partaking in a use-of-force assessment scenario. Results show recruit's decision making was more aligned with an intuitive style rather than an analytical style. Recruits reported experiencing perceptual, cognitive, and physiological impairments that influenced the way they assessed the situation and affected their ability to successfully execute force techniques. The findings provide valuable insights into the theoretical knowledge around police decision making and how officers are making use-offorce decisions in the field. This has real-world implications for training/education and could help reduce the effects of decision-making impairments.
\end{abstract}

Keywords: police use of force; decision making; naturalistic decision making; law enforcement

Dolice encounters that result in force evolve in rapid, dynamic, and stressful conditions. Poor decision making can potentially lead to dire consequences such as civil liability,

\footnotetext{
AUTHORS' NOTE: The authors would like to thank the Queensland Police Service (QPS) trainers, especially Senior Sergeant Damien Hayden, for their help and support with the data collection. The authors acknowledge the assistance provided by the QPS. The views expressed in this material are those of the authors and are not those of the QPS. Responsibility for any errors of omission or commission remains with the authors. The QPS expressly disclaims any liability for any damage resulting from the use of the material contained in this publication and will not be responsible for any loss, howsoever arising, from use of or reliance on this material. Correspondence concerning this article should be addressed to Kelly A. Hine, Centre for Social Research \& Methods, The Australian National University, Room 2.24, Beryl Rawson Building, Ellery Crescent, Canberra, Australian Capital Territory 2601, Australia; e-mail: kelly.hine@anu.edu.au.
} 
unrest, injury, and death. Several recent cases of deadly force by police in the United States have resulted in social movements that question police use of force (such as "Black Lives Matter" and "Hands Up, Don't Shoot"), emphasizing public demand to better understand police decisions. In response, major law enforcement groups have recently produced policing guidelines that stress the importance of de-escalation in police-citizen encounters, to avoid or reduce violent behavior (see International Association of Chiefs of Police, 2017; Police Executive Research Forum [PERF], 2016), and PERF (2016) offers a critical decision-making model to assist officers in such situations. Previous use of force literature has focused on factors associated with force, and the outcomes of force, while paying little attention to how officers make force decisions (Hine, Porter, Westera, Alpert, \& Allen, 2018). This study examines the process police officers use to make decisions about force in a training scenario. The findings provide insights into how officers make decisions in the field, thereby providing a platform for training, policy, and procedures on use of force decision making that can be used as a model in all police agencies.

Before providing the details of the present study, we review the literature to determine the factors that likely influence force decisions. However, while researchers are beginning to understand what is occurring during use of force encounters and when officers are making decisions about force, little is known about how they make those decisions. Our review, therefore, then turns to decision-making processes, highlighting an emerging approach to analyzing decision making, Naturalistic Decision Making (NDM), as a useful approach to examining police decisions about use of force.

\section{FACTORS INFLUENCING POLICE DECISIONS}

While it is difficult to know and examine what someone is thinking, there has been some progress in understanding factors that influence police decisions. Some police researchers have examined factors that affect officers' decisions to engage in law enforcement activities. Researchers have examined officers' decisions to stop and question some citizens and not others (Alpert, Dunham, Stroshine, Bennett, \& MacDonald, 2004; Phillips \& Sobol, 2012) or to stop and frisk (Fradella, Morrow, \& White, 2016; White \& Fradella, 2016). More specific to use of force decisions, researchers have consistently found that the strongest predictor of police using force is the suspect's behavior, particularly when the suspect is being noncompliant and resisting arrest (see Adam, 2015; Hine, Porter, Westera, \& Alpert, 2016; Terrill, 2005; Terrill \& Mastrofski, 2002). Furthermore, clear and strict policies have been found to be an effective tool in controlling discretionary decision making about the use of deadly force (Ferdik, Kaminski, Cooney, \& Sevigny, 2014; Fyfe, 1979, 1981, 1982; Terrill \& Paoline, 2017; White, 2001).

Stenning et al. (2009) explored decision making in more detail to examine officers' actual thoughts about the use of force. Their examination of officers from seven different countries found commonalities in the way officers justified force (such as the legal responsibility to make arrests and as a legitimate response to suspect resistance). Furthermore, Davies (2015) surveyed recruits to gain clearer insights into the factors that influenced officers' use of force decisions. She found threat/safety, justification, and situational factors all influenced recruits' decisions to shoot. Most recently, Hine et al. (2018) found recruits were considering suspect and situation factors when making decisions about force and, moreover, were using these factors to assess threat and suitability of force type. These findings indicate that a variety of factors about the person and the situation might affect an officer's decisions and actions; what remains unclear is how officers are making these force decisions. 
Binder and Scharf (1980) proposed that the decision to use force (or not use force) is not singular, but rather based on a series of choices. They suggested the final decision is contingent upon a sequence of decisions and reactions. The notion of temporal unfolding of decisions is evidenced throughout the policing literature (Bayley, 1986; Fyfe, 1988; Sykes \& Brent, 1983; Terrill, 2003, 2005; Toch, 1996). This highlights the dynamic nature of police use of force encounters, with several decision points throughout, and information and choices made at prior stages affecting decisions at later stages. Decision making is, therefore, a process. Knowledge of this process will help prepare officers for decisions during encounters with citizens.

Outside of the use of force arena, some police research has explored how early information can influence decision-making processes by examining the effects of priming and expectancy prior to encounters on arrest decisions. R. R. Johnson (2009) found officers were more likely to make drug arrests if they perceived that their agency prioritized and rewarded them. Using vignettes, R. R. Johnson (2013) further found that officers primed for negative affect (by thinking about a personal family conflict) were more likely to make an arrest compared with officers primed for positive affect (by thinking about a happy family experience). However, Mitchell and Flin (2007) found that "threat" versus "neutral" briefings given prior to firearms training simulation exercises had no significant influence on officers' decisions to shoot. It is likely, then, that the information officers receive prior to, and during, an event influences their decisions. It is unclear how officers may process this information when making decisions during a force encounter, particularly regarding the style of decision making (such as considering all options before making decisions or basing decisions on instinct).

\section{DECISION-MAKING PROCESSES}

G. Klein (2008) describes making a decision as "committing oneself to a course of action where plausible alternatives exist, even if the person does not identify or compare these alternatives" (p. 457). While a variety of decision-making processes have been proposed within the literature, the dual process model has dominated decision-making research (Brown \& Daus, 2015; Evans, 2008; Kruglanski \& Orehek, 2007; Wang, Highhouse, Lake, Petersen, \& Rada, 2015). This model consists of two processes labeled as "intuitive" and "analytical" (Behling, Gifford, \& Tolliver, 1980; Hunt, Krzystofiak, Meindl, \& Yousry, 1989). An intuitive style of thinking is unconscious, automatic, quick, and effortless in nature. It involves recognizing and identifying cues, and then matching them to patterns organized in the individual's long-term memory (Allen, 2011; Sinclair, 2010). This process is often described as a "gut feeling" (Evans, 2008; Kruglanski \& Orehek, 2007) or a "hunch" (Kenneth, 2010). For example, nurses described a sense of "knowing" the best course of action that was gained by experience, which reflects similar findings in other professions such as physicians and biologists (Agan, 1987). Evans (2008) reviewed the literature and identified 13 various labels attached to the intuitive processing style, including System 1, automatic, and impulsive, among others. Her review also identified 23 attributes associated with an intuitive decision-making style, including unconscious, implicit, automatic, low effort, and rapid, among others. Intuitive decision making uses heuristics (or schemas) which speed up the decision-making process. In policing, decision-making research has focused on automated implicit biases of officers. 
Smith and Alpert (2007) suggested that racial biases are formed by officers after repeated contact with minorities, which form schemas for future encounters (see also Correll, Park, Judd, \& Wittenbrink, 2002; James, James, \& Vila, 2016; James, Klinger, \& Vila, 2014; James, Vila, \& Daratha, 2012). While heuristics can lead to rapid decision making, they are often considered to lead to errors and biases. However, just because a decision is made using heuristics does not necessarily mean it will be inaccurate. More often than not, intuitive decision making can lead to fast and accurate decisions (Cohen, 1981).

In contrast, analytical decision making is a more conscious, time-consuming, and effortful process that involves weighing up all options individually and choosing the best (Kahneman \& Lovallo, 1993). Evans's (2008) review found various labels were attached to analytical decision making, including System 2, controlled, rational, systematic, and reflective, among others. Attributes found to be ascribed to analytical decision making include conscious, explicit, controlled, high effort, and slow (Evans, 2008). Analytical decision making is often considered to lead to correct and optimum decisions. However, it has also been suggested to be a hindrance in situations where rapid decision making is required, and complex tasks are involved (Allen, 2011).

\section{NATURALISTIC DECISION MAKING (NDM)}

During high-pressure situations, including some police-citizen encounters, officers may not have the luxury of making slow, considered analytical decisions and, instead, rely on intuition and experience (via real-world exposure or training; Alpert \& Rojek, 2011; Dror, 2007). Indeed, Fyfe (2015) suggested that a "split-second syndrome" exists whereby rapid decision making inhibits diagnostic capabilities, resulting in bad decisions. However, it can be difficult to study an officer's thoughts and decision processes in situations where force is used. Traditional decision-making studies have relied on questionnaires administered to people in the safe environment of an office or even their own home (Orasanu \& Connolly, 1993; Zsambok \& Klein, 1997). However, the environment can affect decision making: People may make or explain decisions differently in a real-world setting (with all the pressures that may entail) rather than an artificial environment.

A relatively recent approach that may usefully apply to police decisions under pressure is NDM. This approach attempts to understand thought processes in a more dynamic natural setting (G. Klein, 2008). Elements of NDM contexts typically include complex and shifting goals, with multiple actors and influences, time pressure, uncertainty, and high stakes. The NDM approach has been used to study decision making in a variety of such settings as emergency rooms, aviation environments, military operations, and firefighting scenarios (G. Klein, 2008). Police use of force encounters would also present many of the same features (Alpert \& Rojek, 2011) and are prime examples of situations to which the NDM approach would apply. Such intense, uncertain, and rapidly evolving conditions are likely to affect the way that officers are able to make decisions. Hence, to understand police use of force decision-making processes, it is important that they are examined under similarly intense (more naturalistic) circumstances.

As noted, it is unlikely that officers would be able to make slow, analytical decisions in situations that are sufficiently high risk to involve physical force. The NDM approach proposes that experience plays an important role in enabling people to make quick, intuitive, decisions by categorizing information, such as by using heuristics. Indeed, scholars suggest 
that intuition is built on prior experience, where experts are those who can draw from a rich catalog of patterns from previous experiences (G. Klein, 2015). An expert tends to operate at a highly intuitive and subconscious level compared with a novice. Greitzer, Podmore, Robinson, and Ey (2010) outlined that a highly experienced person does not need to consider all options, whereas a moderately experienced person relies on more rule-based decisions (such as if x occurs, then y follows). Finally, novices rely on a more analytical approach. Essentially, NDM takes a knowledge-based approach in that people are said to base decisions on their prior knowledge and experiences. The higher the level of knowledge and expertise, the more intuitive the decision-making process becomes-leading to more accurate and rapid decision making.

NDM proposes the Recognition-Primed Decision (RPD) Model to explain how experts can make rapid decisions without the time-consuming need of comparing all options (G. A. Klein, 1993). The model is based on the idea that decisions are made by matching current situations to past situations (from long-term memory; Zsambok \& Klein, 1997). Experts use mental simulation to imagine the outcome of an action. The model suggests that, rather than looking at all possible options in making a decision, experienced individuals select the first workable option (similar to satisficing heuristics). This suggests that if officers encounter similar situations to those encountered in the past, then they will act more rapidly using an intuitive process. Conversely, if officers encounter a new situation, then this will take longer to access and process, relying on a more analytical approach. Hence, the model is in part intuitive (the use of pattern matching) and in part analytical (the use of mental simulation). It also highlights the importance of variations in training to prepare officers for rapid decision making in the variety of situations that they will encounter in the real world.

\section{IMPAIRMENTS TO DECISION MAKING}

NDM research has highlighted that someone's course of action "inextricably depends on how they understand the situation" (Kaempf, Orasanu, Zsambok, and Klein, 1997, p. 11). Stress may affect how decisions are made and produce impediments to decision making. Several factors throughout an encounter can affect officer performance (the accuracy and efficiency of decisions). There are three main stress responses that affect policing: perceptual, cognitive, and physiological (Andersen \& Gustafsberg, 2016; Arnetz, Arble, Backman, Lynch, \& Lublin, 2013). Perceptual impairments involve distortions in the body's sensors due to the fight or flight response in times of stress, such as experiences of tunnel vision or auditory exclusion (Andersen \& Gustafsberg, 2016). Time can also feel as though it is slowing down and sounds may be amplified or softened (Andersen \& Gustafsberg, 2016). Perceptual impairments can affect how officers perceive the situation. Interviews with 80 officers who had shot citizens in a total of 113 incidents revealed that almost all officers had experienced altered perceptions - most commonly diminished sound, tunnel vision, and time distortions (Klinger, 2004). More broadly, this may also include issues of situational awareness; for instance, an officer may narrow their attention to one particular aspect of the encounter to the exclusion of seeing and hearing other crucial information. Cognitive impairments include memory deficits, such as an officer's ability to encode, store, and recall information from memory. This can affect how officers make logical decisions, including their ability to draw on stored information such as training techniques and tactics 
(B. Johnson, 2008). Finally, physiological impairments affect fine motor skills due to the body's adrenalin response of fight or flight in times of stress. While this stress response helps to improve gross motor skills (running, punching/kicking, etc.), the increase in heart rate and respiration can counteractively decrease coordination and accuracy (e.g., the fine motor skills needed in precision shooting; Everly \& Lating, 2013; B. Johnson, 2008). Physiological impairments can affect how officers physically react - their ability to use force, which in turn affects their decisions about the use of force. Identifying impairments to officers' decision making can assist education and training practices to control them, or prevent them from occurring, and in turn reduce their impact on decision making during police use of force encounters.

\section{THE PRESENT STUDY}

The present study applies the NDM framework to explore how police officers are making decisions in situations that result in force. The NDM framework advocates exploring decision making in naturalistic settings and allows decision-making processes to be examined in terms of the level of analysis or intuition that is evident, as well as the role of experience in decision making. The present study explores police recruits' decision-making processes and impairments. Recruits provide an interesting population as they possess a moderate level of experience-while they are more experienced than the average citizen (as at this point they have received all the training required to be an operational officer), they do not yet possess real-world experience. The present study is one of the first to examine how police make use of force decisions in a naturalistic environment; therefore, the use of recruits also provides a baseline from which future research can explore the effects of real-world experience on decision making. As proposed by NDM, under uncertain and time-pressured circumstances of potentially volatile police encounters, it is predicted that officers will more likely make intuitive decisions, rather than slower, systematic analytical decisions. However, due to their lack of real-world experience, recruits may not yet be able to rely fully on intuition. Instead they may use rule-based decisions and match circumstances to their previous training and experiences. Understanding the processes officers are using to make decisions about their use of force will provide insights into why officers are making certain decisions. This can inform policy makers and trainers as to best practices for preparing officers for police-citizen encounters to minimize or avoid uses of force.

\section{METHOD}

\section{DATA SOURCE}

The data consisted of audio recordings of debriefs between Queensland Police Service (QPS) recruits and trainers, in which recruits were asked to describe their decisions and actions in relation to a simulated scenario. As part of their final assessment (at the end of their 25-week training program), recruits partake in two role-playing scenarios (described below). The debrief session took place immediately after the scenario. The debrief recordings were on average $15 \mathrm{~min}$ long, ranging from 3 to $40 \mathrm{~min}$, and transcribed by one of the authors. 
TABLE 1: Frequency of Force Types per Overall Decisions

\begin{tabular}{|c|c|c|}
\hline Force type & Description & Frequency \\
\hline Presence & $\begin{array}{l}\text { The presence of a uniformed officer at the } \\
\text { scene }\end{array}$ & $\begin{array}{l}\text { All scenarios commenced with } \\
\text { police presence }\end{array}$ \\
\hline Communication skills & $\begin{array}{l}\text { Verbal directions and conversations to } \\
\text { persuade compliance }\end{array}$ & $\begin{array}{l}\text { All scenarios commenced with } \\
\text { communication skills }\end{array}$ \\
\hline $\begin{array}{l}\text { Situational } \\
\text { containment }\end{array}$ & $\begin{array}{l}\text { Restriction of access-may include creating } \\
\text { barricades, lockdowns, etc. }\end{array}$ & 0 \\
\hline Tactical withdrawal & $\begin{array}{l}\text { Strategic retreat to remove safely from } \\
\text { situation }\end{array}$ & 0 \\
\hline $\begin{array}{l}\text { Restraining } \\
\text { accoutrements }\end{array}$ & $\begin{array}{l}\text { Use of restraining accoutrements such as } \\
\text { handcuffs to restrain the subject }\end{array}$ & $\begin{array}{l}\text { All scenarios ended with the } \\
\text { role-playing suspect being } \\
\text { handcuffed and searched }\end{array}$ \\
\hline Open hand tactics & $\begin{array}{l}\text { Blocking, restraining, joint locks, pressure } \\
\text { points, pain compliance. Does not include } \\
\text { punching, kicking, etc. }\end{array}$ & 80 \\
\hline Closed hand tactics & Includes punches, kicks, knee strikes, etc. & \\
\hline Baton & Impact weapon & 6 \\
\hline $\begin{array}{l}\text { Oleoresin capsicum } \\
\text { (OC) spray }\end{array}$ & $\begin{array}{l}\text { Gas spray that can result in eye swelling, } \\
\text { temporary blindness, pain, etc. }\end{array}$ & 10 \\
\hline $\begin{array}{l}\text { Conducted energy } \\
\text { weapon (Taser) }\end{array}$ & $\begin{array}{l}\text { Stunning device that produces an electric } \\
\text { shock that can result in temporary muscle } \\
\text { contractions and incapacitation }\end{array}$ & 17 \\
\hline Firearm & Service issue firearm & 0 \\
\hline
\end{tabular}

\section{SAMPLE}

All recruits from one intake (96 recruits) between December 2012 and February 2013 were invited to participate, which resulted in the consent of 91 recruits. The sample comprised recruits who had acquired all the training required to become operational field officers (after the successful completion of the scenario assessment, this sample will be making real-world force decisions). Participants were mostly male, with $23.48 \%$ female, which is reflective of the proportion of sworn officers in Queensland. The average age was 28 years (range, 20-46 years).

\section{THE SCENARIOS}

The role-play scenarios formed part of the existing assessment for QPS recruits and were designed to be as realistic as possible, allowing the recruits to use force. ${ }^{1}$ During each scenario, recruits interact with a role-player in real time to provide a tactile and responsive environment reflective of the real world (as opposed to vignettes or virtual simulations). Officers were verbally briefed with a minimal amount of information before entering the scene, designed so that they would enter an ambiguous and dynamic situation. Recruits were tasked with resolving the "incident" and were able to respond using any of the force options provided by the QPS (see Table 1), although, for safety reasons, some of the accoutrements were replaced with simulated versions. Trainers played the role of a suspect. ${ }^{2}$ Role-players escalated or de-escalated their behavior in response to recruits' actions, but this behavior was scripted to ensure a degree of consistency. All recruits participated in two scenarios (domestic violence and disturbance) in pairs alternating the role of lead officer 
TABLE 2: Scenario Descriptions and Debrief Questions

\begin{tabular}{|c|c|c|}
\hline Scenario & Description & Debrief questions \\
\hline $\begin{array}{l}\text { Domestic } \\
\text { violence }\end{array}$ & $\begin{array}{l}\text { Recruits were briefed that a victim had attended the } \\
\text { police station to make a domestic violence complaint } \\
\text { and an address was provided. The scenario involved } \\
\text { the recruits attending the address to investigate the } \\
\text { complaint. The scenario is designed to require the } \\
\text { recruits to detain a suspect for domestic violence. } \\
\text { All scenarios commenced with recruits using } \\
\text { communication skills and the role-playing suspect } \\
\text { provided slight resistance by not cooperating with } \\
\text { recruits' directions and verbal commands. The } \\
\text { suspect displays this resistance verbally only- } \\
\text { without any physical threats or assaults. The suspect } \\
\text { concealed a knife in their boot which was designed } \\
\text { for recruits to locate and recover during the search of } \\
\text { the suspect. Suspects are then scripted to respond } \\
\text { based on recruits' decisions; to physically resist any } \\
\text { contact by recruits, but to comply with the deployment } \\
\text { of OC spray (i.e., being sprayed) and the presentation } \\
\text { of firearms or Tasers. } \\
\text { Recruits are briefed that the scenario involves reports } \\
\text { of a person under the influence of alcohol creating } \\
\text { a disturbance outside a nightclub. When recruits } \\
\text { arrive at the scene the suspect is banging on the } \\
\text { wall demanding to be let back into the nightclub to } \\
\text { collect their belongings. All recruits initially used } \\
\text { communication skills; however, the suspect ignores } \\
\text { officers' directions and verbal commands. As above, } \\
\text { suspects are then scripted to respond based on } \\
\text { recruits' decisions; to physically resist any contact } \\
\text { by recruits, but to comply with the deployment of OC } \\
\text { spray (i.e., being sprayed) and the presentation of } \\
\text { firearms or Tasers (CEW weapon). }\end{array}$ & $\begin{array}{l}\text { At the conclusion of the scenario, } \\
\text { trainers conduct a debrief with recruits } \\
\text { specifically addressing the following: } \\
\text { Explain threat assessment process } \\
\text { What tactical considerations existed? } \\
\text { What use of force options was } \\
\text { considered/used? } \\
\text { Discussion that "Situational Use of } \\
\text { Force" model is not restrictive and that } \\
\text { officers can escalate or de-escalate } \\
\text { their use of force as necessary } \\
\text { Were their actions authorized? } \\
\text { Were they justified? } \\
\text { Were the use of force options } \\
\text { reasonable, proportionate, and } \\
\text { appropriate? } \\
\text { Would the use of force options be } \\
\text { legally defensible? } \\
\text { Were their actions tactically sound and } \\
\text { effective? } \\
\text { What went well? } \\
\text { What would you do differently in future? } \\
\text { Discussion of good practice }\end{array}$ \\
\hline
\end{tabular}

Note. $\mathrm{OC}=$ Oleoresin Capsicum; CEW = conducted energy weapon .

(see Table 2 for details). Adding to the high-stakes environment was the fact that recruits were being assessed on the situation and must pass to graduate from the academy.

\section{ANALYSIS AND CODING}

Thematic analysis of the transcripts was conducted using NVivo software to manage and organize the data. Coding was conducted by two authors who double-coded all transcripts and agreement was reached. Cohen's $\kappa$ indicated a good inter-rater reliability, $\kappa=.78$, $p<.001$. A code book was developed from the NDM literature. Broad themes included decision-making processes (analytical and intuitive styles) and decision-making impairments (perceptual, cognitive, and physiological). To identify decision-making processes, all force decisions were first identified as the unit of analysis. Then, the force decision was coded (see below). Impairments were extracted independent of the force decision and then broken down into perceptual, cognitive, and physiological impairments. These are described below. 


\section{Force Decisions}

Force decisions were coded as the decision to use or not to use force, or to use higher or lower levels of force. Force was defined according to the QPS force options (see Table 1). To determine decision-making styles, searches for Analytical and Intuitive themes were conducted. Force decisions were coded as Analytical when officers were systematically considering all possible options. Analytical decisions were coded according to Evans's (2008) analytical attributes and were coded if recruits' descriptions indicated that they were conscious, explicit, controlled, slow, reflective, logical, sequential, or high effort. In addition, to capture the analytical part of the RPD model, mental simulation was coded if the recruit described imagining the outcome before deciding on their actions.

Conversely, Intuitive force decisions were coded if the recruit described an automated response such as a "gut feeling" or a "hunch." In line with Evans (2008), decisions were also ascribed to intuition if they were deemed unconscious, implicit, automatic, rapid, or low effort. In addition, intuitive decisions are based on pattern matching and heuristics. Accordingly, intuitive decisions were further broken down to include heuristics, such as satisficing, elimination by aspects, representative heuristics, availability heuristics, and anchoring. Pattern matching also captured the intuitive part of the RPD model and was coded when officers described recognizing similar features of the present encounter to those of past experience.

NDM proposes that experience plays an important role in intuitive decision making. Experts are said to draw from prior experiences, whereas novices rely on rule-based decisions. Accordingly, to identify the role that experience played in the recruit's decision making, prior experience and rule-based decisions were coded. Previous experience was coded when recruits referred to using previous experiences in making decisions (such as their training, previous occupational experiences, or other life experiences) and rule-based decisions was coded when recruits expressed decisions were based on an "if, then" decisionmaking process.

\section{Decision-Making Impairments}

Decision-making impairments were coded as Perceptual, Cognitive, and Physiological. Perceptual impairments included reported experiences that could be considered evidence for sensory distortions. This also included broader situational awareness issues where recruits focus on one aspect of the encounter to the exclusion of hearing or seeing other aspects. Cognitive impairments were coded if the recruit described memory deficits or errors in their logical thinking, whereas physiological impairments were coded if fine motor skills were reportedly affected.

\section{RESULTS}

\section{DECISION-MAKING PROCESSES}

Examination of how recruits were making decisions found no evidence of recruits using a purely analytical approach to their force decisions (where all force options were considered systematically). Of the decisions coded, $51.35 \%$ considered one alternative option, $29.73 \%$ considered two alternative options, and $18.92 \%$ considered three alternative options from the eight ${ }^{3}$ possible options available for coding purposes. There were no occurrences 
of recruits describing that they considered four or more options when making their decisions. To illustrate, the following recruit described considering the use of a Taser, and ruled out the use of OC spray, and actually decided to use hands-on tactics:

Honestly, when I first saw him I thought he is a big guy and if this turns bad I will consider using Taser. Just cause he's so big. But we were kind of really close weren't we and he wasn't facing us so I thought hands on, let's just do it. I didn't want to use OC in case there's heaps of people around. (Recruit 71)

Because recruits were only considering a small number of force options, this suggests they were using an intuitive approach when making decisions about force. A small number $(8.79 \%)$ of recruits also described an automated response reflective of intuitive decision making. When discussing the successful execution of force, recruits described not realizing how the result had happened. These recruits spoke about how smooth, quick, and natural it felt, but not the actual logistics of the maneuver:

I think it just happened so quick. It felt really, really smooth. He wasn't giving us his arm. He fell pretty quickly but next thing I remember is going for his arm and having him in an arm lock and that all happened probably in what feels like 30 seconds. (Recruit 2)

Many of the recruits' responses provided evidence that they were relying on a variety of heuristics as part of this intuitive approach (81.32\% of decisions). A deeper examination of the heuristics used shows evidence of recruits using elimination-by-aspects heuristics $(51.35 \%)$ where recruits used categories as a process of exclusion to make their force decision. In particular, recruits spoke of "accoutrements" (categorizing Tasers, OC spray, baton, firearm, etc.) in terms of eliminating them all as a force option: "at that point, we deemed it was appropriate to go open hand tactics - there was nothing really raising the threat level for an accoutrement at that point" (Recruit 16). In addition, there was evidence to suggest that recruits were using satisficing heuristics in their decisions (31.25\% of decisions). Recruits would select the first workable option under the time-pressured and difficult situations, "so, it was pretty much an option of hands-on. If that didn't work, we could have gone to an accoutrement" (Recruit 22). Recruits were also using availability heuristics to make decisions (15.25\% of decisions). For example, in response to the trainer's question about how well the recruits had executed a maneuver, she or he responded that they had previously performed the same maneuver in similar circumstances during training the previous day, so it was fresh in their memories "because we'd done a similar scenario in the practice ones where we had the role player up against the wall and she was just squirming with her legs" (Recruit 21).

While these findings indicate that recruits used an intuitive approach to make use of force decisions, the above quote illustrates that recruits were also using pattern matching to make intuitive decisions. In particular, recruits were matching the current situation to previous situations during training. In addition, most recruits $(52.74 \%$ of recruits) described the use of mental simulation to envision how the encounter would unfold, as proposed by the RPD model. The use of mental simulation is conscious and deliberate, which reflects the analytical part of the RPD model. While recruits did not use an analytical approach to systematically consider all options, they did use analytical thinking in the form of mental simulation: 
I considered that if I'd [OC] sprayed him, it would have antagonized the situation-he may have come at us anyway leaving us no choice but to take him down. I thought eliminate the OC spay and Taser and go straight for closed-hand tactics. (Recruit 122)

Reflecting their experience level, recruits demonstrated a reliance on rule-based decisions. Recruits assessed that if the suspect behaved in a certain way or a certain situation was presented, then a particular type of force should be chosen. For instance, the following recruit explained that they would use a different type of force (i.e., hands-on or OC spray) depending on the different circumstances (i.e., intoxicated or presence of bystanders, respectively):

I would have started with presence and communication skills, but given that he was kicking the walls, then there may be a bit more of an aggressive use of force maybe. The hands-on, given that he had some drink. Potentially OC spray if there was no one else around but, being outside a bar, it may not have been an option. (Recruit 68)

Some recruits' responses (10.98\%) suggested that they also drew on prior experiences such as previous occupations or police training (like the previous quote where the recruits drew on their experience of training). One recruit explained that he or she was able to provide clearer directions than other recruits because he or she was able to draw on his or her previous experience as a life guard and therefore was able to verbally control the situation rather than relying on accoutrements in his or her force decisions: "I used to be a life guard, and talking to a lot of tourists, telling them where not to swim, I used to use my hand" (Recruit 22). While another recruit talked about childhood experiences when describing their approach. The recruit explained that when he or she was unable to successfully execute a maneuver (due to the suspect being sweaty), he or she drew on his or her experiences of school yard wrestling: "yeah, I ended up improvising and going back to the school yard" (Recruit 108). Overall, most of the time recruits were considering only one or two alternative force options. This lack of systematic consideration of the full range of alternatives, as well as evidence that heuristics were in use, suggests that recruits were using intuitive decision making.

\section{IMPAIRMENTS}

Recruits reported experiencing impairments in all three areas (perceptual, cognitive, and physiological) during the scenarios. However, most often recruits reported experiencing cognitive impairments. More than a third (34.07\%) of recruits experienced cognitive impairments which can impede officers' ability to recall information that can help with decision making during the scenario such as training and tactics. Mostly, recruits reported memory malfunctions during the encounter such as having a "mind blank." To illustrate, one recruit "blanked" on both his or her partner's name and his or her own name: "in both [scenarios] you forgot my name, you were like Constable umm and you forgot your own name" (Recruit 108). Other examples of memory malfunctions included recruits not realizing how they got to a certain point or forgetting how to execute a maneuver or procedure:

Trainer: And what did you notice about your Taser?

Recruit 13: I probably didn't turn it on or something...

Trainer: You didn't turn it on, which is why the role player swiped at it ... You're fortunate that in the last split second you realized you hadn't turned it on and you went bang bang almost in a simultaneous 
movement and you managed to activate it just as he was about to sweep it out of your hands. So you weren't even conscious of that fact?

Recruit 13: No

While only $10.99 \%$ of recruits reported experiencing perceptual impairments, such impairments can impede officers' abilities to assess the situation (what they see and hear). A small number (7.69\%) of recruits suffered failures of situational awareness similar to tunnel vision, where they focused on a particular aspect of the encounter ignoring other important information. For example, one recruit described focusing on the suspect's behavior to the extent that it resulted in providing incorrect identifying information:

I stuffed up on the date of birth, wholly and solely because I was more looking at his mood, his positioning and his stance and the rest of it and not paying a huge amount of attention to what he was saying. (Recruit 145)

Another recruit explained that the situational awareness failures of his or her partner, who was focusing on one of the suspect's arms, resulted in his or her partner's unawareness of the rest of the suspect's body (such as the legs) which could potentially result in officers being kicked and injured: "[partner] sort of grabbed the arm and was just looking at the arm and wasn't looking at what his legs were doing or what his head was doing" (Recruit 2). Three recruits experienced auditory exclusion - they did not hear crucial information that was being said by their partner, the suspect, or the trainer. The consequences of auditory exclusion are exemplified in the following case. The recruit was using hand tactics to control the situation; however, the maneuver was becoming potentially dangerous and started to put the role-player at risk of injury. The trainer (and others) attempted to intervene; however, the recruit did not "hear" the warning to stop: "there was three of us yelling at you to back off and for whatever reason you didn't hear it because it does get like that" (Trainer to Recruit 139).

Physiological impairments can hinder fine motor skills and the ability to execute force techniques and use accoutrements. This can restrict their decision options (i.e., inability to successfully execute a maneuver, which, therefore, is not considered as an option) or the effectiveness of the decision outcome. Recruits reported suffering physiological symptoms $(7.69 \%)$ such as rushes of adrenalin, shortness of breath, tiredness, dry mouth, and shakes. One recruit described that because he or she was so "amped up" and rushing forward with the procedure, he or she forgot to do part of the standard procedure: "I think I just got so amped with the adrenalin pumping. I raced in and after I started, I thought shit, I've forgotten something here" (Recruit 69). Another recruit explained that physiological impairments affected his or her ability to communicate. This resulted in time delays and a shift in his or her focus, affecting the decision-making process: "yeah for me, a dry mouth and its odd and it kind of turns into Gandhi's flip flop ${ }^{4}$ - it's just weird" (Recruit 122). The effects of physiological impairments to successfully execute force maneuvers were described by one of the recruits. The recruit described that, due to the stress response of shaking, he or she was unable to successfully execute his or her force technique chosen and as a result needed to change tactics: "my knee was shaking so much, because my knees shake when I'm stressed, and my hand was shaking a bit" (Recruit 1). 
Hence, most recruits reported cognitive, perceptual, and physiological impairments during the scenarios and provided insights into the consequences of these impairments. In particular, consequences included the potential of being misinformed, resulting in incorrect assessments of the situation, potential use of excessive and unnecessary force, or the failure to successfully execute force tactics and accoutrements, which could result in injury to officers or suspects. Yet some recruits $(3.30 \%)$ reported they experienced no or minimal impairments. For example, one recruit, when asked whether they found it difficult under the stress, replied,

No-I certainly think I've received sufficient training to do that. And the more you do it, the better you get at it. And the more experience you get under your belt, it will become second nature to you. (Recruit 122)

This recruit highlights the important role that experience plays. Experience not only aids in rapid decision making but may also help to manage the stress of the event and allow for clearer information processing.

\section{DISCUSSION}

The present study applied a naturalistic decision-making framework to explore how police make decisions about using force. Overall, recruits were using a decision-making style that was more aligned to intuitive rather than analytical decision-making processes. This was evidenced by automatic unconscious decision making and the use of pattern matching and heuristics. However, recruits were using mental simulation to envision the outcome, which is consistent with the RPD model and indicative of analytical thinking. The findings also revealed impairments of the decision-making process. Recruits described cognitive, perceptual, and physiological impairments, with some resulting in potentially dangerous situations or inappropriate uses of force. These findings provide insights into how officers are making decisions about force in the field and can help inform the development of appropriate policies, procedures, and training. The findings also demonstrate the benefits of scenario-based training to allow recruits to practice and make mistakes in "safe" environments where they can reflect on their decision making.

\section{HOW WERE RECRUITS MAKING DECISIONS?}

During the role-played use of force scenarios, recruits appeared to be using an intuitive decision-making process. This is consistent with the prediction that, during uncertain and time-pressured circumstances, people are more likely to make intuitive decisions (Alpert \& Rojek, 2011; Dror, 2007; G. Klein, 2008). There was no indication that recruits were using a slow and sequential process reflective of analytical decision making to consider all available options. However, there was evidence that recruits were using pattern matching and heuristics to make decisions about the use of force, as well as mental simulations to envision the outcomes of various options, consistent with the RPD model. This process is deliberate and analytical in nature. Hence, overall officers were using a blend of intuitive and analytical decision making consistent with the suggestion that, rather than intuitive and analytical decision making falling on opposite ends of a continuum, they are 
independent decision-making styles that can work together (Allen, 2011; G. A. Klein, 1993; Wang et al., 2015).

NDM research (and the RPD model) highlights the importance of expertise in intuitive decision making. Recruits were relying on rule-based decisions. This is consistent with Greitzer et al.'s (2010) description of a moderately experienced person. While recruits are more experienced than the average citizen, and those in this study had received all the training and experience required to be active field officers, they had not yet gained field experience. To become intuitive expert decision makers, further training and practice are required.

If police are using an intuitive decision-making style, a mismatch exists between realworld decision making and the systematic approach recommended in policies and procedures. Allen (2011) highlighted that, in typical policing legislation and policies, imposed rules and guidelines are structured toward analytical decision making. The expectations are for police to use and justify decisions based on careful, rational, analytical processes and not on intuitive gut feelings. For instance, Queensland police officers are trained using the Situational Use of Force Model in which officers are encouraged to consider all options (QPS, 2016). Allen (2011) found that, despite being provided with information and instructions that encouraged compliance of analytical decision making, officers still used intuitive decision-making styles.

The findings of the present study support the view that applying the traditional analytical decision-making theories to policies is likely to be ineffective in use of force scenarios. Considering all options may be difficult and even impossible in high-risk environments due to the time pressure, task complexity, and environmental uncertainty. This has implications for how policies and procedures are constructed. To best prepare officers for potential use of force encounters, use of force policies and training procedures should acknowledge and aid intuitive decision making during potential use of force encounters. In the present study, there was evidence of recruits applying heuristics to speed up the decision-making process. The use of heuristics may be helpful in bridging the gap between the analytical style wanted in the policies and the intuitive style that is likely to occur during actual use of force encounters. Indeed, the key to narrowing the discord may lie in a combination of simplified policies and models, education of heuristics, and consistent and repetitive training in using decision-making models. For example, PERF's (2016) guiding principles provide a good starting point for informing police agencies about best practices for policies, decision models, and training. PERF's (2016) Critical Decision-Making Model aims to provide a structured, yet easy-to-use model to guide officers' decisions. However, PERF also stresses the importance of repetition and practice in using the model to develop "muscle memory" for rapid and fluent (intuitive) responses.

\section{WHAT WERE THE IMPAIRMENTS TO DECISION-MAKING PROCESSES?}

In support of the NDM context of the scenario-based training utilized in this study, recruits reported feeling under stress and experiencing a number of associated impairments. Impairments to decision-making processes may help to explain unnecessary or excessive force used by police unintentionally. Indeed, Fyfe (2015) highlighted that beyond "extralegal" reasons, police violence can occur unnecessarily when well-meaning officers are incapable of dealing with the situation. Recruits expressed experiencing cognitive, perceptual, and physiological impairments. Recruits experienced cognitive impairments such as "mind blanks" and memory malfunctions. The impact of stress on memory can result 
in the inability to remember simple tasks (B. Johnson, 2008). Recruits also experienced perceptual impairments can influence the way police hear and see the situation (Andersen \& Gustafsberg, 2016). Kaempf et al. (1997) highlighted the importance of accurately assessing the situation as the course of action is selected based on this assessment. Perceptual impairments can lead to misinformation and an incorrect assessment of the situation. Similar to Klinger (2004), the present study found recruits experienced auditory exclusion and perceptual awareness failures similar to tunnel vision. Finally, physiological impairments affected some recruits' ability to execute force techniques and accoutrements during use of force encounters (B. Johnson, 2008). The presence of these impairments provides insights into why officers may make poor decisions, resulting in the use of too much or too little force. Incorrect assessment of the situation, memory malfunctions, and physiological difficulties may adversely affect decisions and the ability to control a suspect. Furthermore, due to cognitive, perceptual, or physiological impairments, officers may be unaware of the extent of their use of force in controlling a situation and may be unintentionally using excessive or unnecessary force. During police use of force scenarios, officers are more likely to make decisions intuitively — such impairments can impede this process.

\section{IMPLICATIONS}

These findings highlight the importance of simplified policies and scenario-based training for police. Officers need to understand all available force options and the strength, limitations, and suitability of each. Through training, schemas (heuristics) can be learned and then called upon when in high-pressure situations to guide decision making. This will limit the cognitive capacity needed to make decisions by only considering relevant options - not every option. Furthermore, officers need to develop the skills to use the different force options implicitly, so valuable mental resources (that could be used for decision making) are not dedicated to operating the equipment. This means that skill development and simulating real-life conditions need to be continually conducted once foundation skills are learnt.

Training should focus on potential decision-making impairments, to prepare officers for such experiences and to reduce their effects. For example, Andersen and Gustafsberg (2016) showed that officers provided with a program designed to control stress during critical incidents performed better and made a greater number of correct force decisions than officers who did not undertake the program. Stress reduction techniques may also include training simulations in realistic and tactile environments. Weekly combat sports (such as martial arts) may improve responses to high-anxiety situations (Renden, 2015), while stress-inducing activities (such as shooting a target while standing on one foot) also show promising results to reducing the effects of impairments (Polis Solutions, 2018). Finally, meditation practices including mindfulness may help coping with stressful situations (Yeoman, 2017).

In addition, our findings show the value of "live" training and debriefing to provide a safe environment for officers to make and learn from mistakes and understand their behavior and decision making. Frequent and repetitive training through use of force scenarios is needed that is inclusive of a wide variety of variables to best prepare officers for such circumstances. Rajakaruna, Henry, Cutler, and Fairman (2017) found that the focus of training should shift from performance and assessment to one that continually develops skills by practicing and learning. Situations that differ from the typical scenario take longer to process (Belmore \& Hubbard, 1987), and officers who are slower in reacting may be at risk. Hence, variations in training will help to develop a wider range of experiences to draw 
from, resulting in faster decision making. Furthermore, the exposure to the stress inoculation effect of these live conditions will reduce negative stress responses in real-world encounters (Andersen \& Gustafsberg, 2016). Therefore, educators and trainers should consider incorporating training methods that increase officers' awareness (Bargh, Chaiken, Raymond, \& Hymes, 1996) and provide officers with a wide variety of both typical and atypical training scenarios. Teaming new/probationary officers with more experienced officers could also support continued teachings in real-world settings.

\section{LIMITATIONS AND FUTURE DIRECTIONS}

This is one of only a few studies to explore police use of force decision making and impairments. Future research should replicate and expand the present study to examine the decision-making processes of experienced officers and in real-world situations. The literature would suggest that experienced officers may be even more likely to make decisions rapidly and rely on intuitive decision making. Such studies can provide further insights into the heuristics being used, and their outcomes, which in turn will inform best practices for future training and policies.

Measuring decision-making processes is difficult, however, as it relies on the person's ability for metacognition. The present study's results show that recruits were able to articulate their decisions to some extent, but it is unknown to what degree this truly represents their internal processes. While some people are better at metacognition than others, most people with normal intelligence are able to engage in metacognitive regulation (Livingston, 2003). Future research could explore other methodological approaches to decision-making measurement to overcome the present study's limitations. Namely, the study was limited to the reliance on officers' retrospective reports. Like anyone's memory for events, these reports are open to bias (e.g., self-justification, rationalization), particularly where stakes are high (e.g., where outcomes might affect an officer's career or have legal implications), and other attributes resulting from the fallibility of memory (e.g., forgetting, misinformation). While the focus of our study is on the process of the decision, and not the decision itself (which may be more affected by these issues), the use of body-worn cameras during the scenario-based training (or from real events) would help to support officers' debrief statements and supplement missing information. In doing so, a more robust body of knowledge that provides insights into decision-making processes can be formed.

\section{CONCLUSION}

This study explored recruits' decision-making processes and impairments during use of force training scenarios and found recruits were primarily making force decisions intuitively. Policies and procedures that rely on systematic and analytical styles of decision making may, therefore, be counterproductive. Furthermore, the recruits experienced perceptual, cognitive, and physiological impairments that affected how some perceived and assessed the situation and their ability to successfully perform force techniques and use accoutrements. These deficiencies could potentially result in unintentional excessive or unnecessary force as well as potentially dangerous situations with risk of injury to the officer or suspect. Education and awareness about decision-making impairments, as well as training for stress reduction and application of heuristics, can potentially reduce the effects of decision-making impairments. Overall, our findings, if put into practice, can help prepare officers for 


\section{potentially dangerous situations and hopefully de-escalate encounters and reduce the use of} force.

\section{NOTES}

1. Naturalistic Decision Making (NDM) research has shown that participants often take studies in artificial environments seriously; for example, Hammond (1993) stated it is not the location of the study by how something is studied and what is being studied that is important.

2. In a small number of cases, fellow recruits role-played the suspect, but only after having completed the assessment themselves.

3. All scenarios commenced with police presence and communication skills and ended with the suspect being handcuffed and searched, therefore, these force options were not included in the coding.

4. Gandhi's flip flop is slang for the effects of a dry mouth.

\section{ORCID iD}

Kelly A. Hine (iD) https://orcid.org/0000-0003-2497-2069

\section{REFERENCES}

Adam, K. (2015). What we know about police use of force. In R. G. Dunham \& G. P. Alpert (Eds.), Critical issues in policing: Contemporary readings (7th ed., pp. 451-467). Long Grove, IL: Waveland Press.

Agan, R. D. (1987). Intuitive knowing as a dimension of nursing. Advances in Nursing Science, 10, 63-70.

Allen, D. (2011). Information behavior and decision making in time-constrained practice: A dual-processing perspective. Journal of the American Society for Information Science and Technology, 62, 2165-2181. doi:10.1002/asi.21601

Alpert, G., Dunham, R., Stroshine, M. S., Bennett, K., \& MacDonald, J. M. (2004). Police officers' decision making and discretion: forming suspicion and making a stop (NCJRS). Washington, DC: U.S. Department of Justice.

Alpert, G., \& Rojek, J. (2011). Frontline police officer assessments of risks and decision making during encounters with offenders. CEPS Briefing Paper, 5, 1-6.

Andersen, J. P., \& Gustafsberg, H. (2016). A training method to improve police use of force decision making: A randomized controlled trial. Sage Open, 6(2), 1-13. doi:10.1177/2158244016638708

Arnetz, B. B., Arble, E., Backman, L., Lynch, A., \& Lublin, A. (2013). Assessment of a prevention program for workrelated stress among urban police officers. International Archives of Occupational and Environmental Health, 86, 79-88. doi:10.1007/s00420-012-0748-6

Bargh, J. A., Chaiken, S., Raymond, P., \& Hymes, C. (1996). The automatic evaluation effect: Unconditional automatic attitude activation with a pronunciation task. Journal of Experimental Social Psychology, 32, 104-128. doi:10.1006/ jesp.1996.0005

Bayley, D. H. (1986). The tactical choices of police patrol officers. Journal of Criminal Justice, 14, 329-348. doi:10.1016/00472352(86)90126-1

Behling, O., Gifford, W. E., \& Tolliver, J. M. (1980). Effects of grouping information on decision making under risk. Decision Sciences, 11, 272-283. doi:10.1111/j.1540-5915.1980.tb01138.x

Belmore, S. M., \& Hubbard, M. L. (1987). The role of advance expectancies in person memory. Journal of Personality and Social Psychology, 53, 61-70. doi:10.1037/0022-3514.53.1.61

Binder, A., \& Scharf, P. (1980). The violent police-citizen encounter. The ANNALS of the American Academy of Political and Social Science, 452, 111-121. doi:10.1177/000271628045200111

Brown, S. G., \& Daus, C. S. (2015). The influence of police officers' decision-making style and anger control on responses to work scenarios. Journal of Applied Research in Memory and Cognition, 4, 294-302. doi:10.1016/j.jarmac.2015.04.001

Cohen, L. J. (1981). Can human irrationality be experimentally demonstrated? Behavioral and Brain Sciences, 4, 317-331. doi:10.1017/S0140525X00009092

Correll, J., Park, B., Judd, C. M., \& Wittenbrink, B. (2002). The police officer's dilemma: Using ethnicity to disambiguate potentially threatening individuals. Journal of Personality and Social Psychology, 83, 1314-1329. doi:10.1037/00223514.83.6.1314

Davies, A. J. (2015). Shoot/do not shoot-What are the influences? The police recruit perspective. Policing and Society: An International Journal of Research and Policy, 27, 494-507. doi:10.1080/10439463.2015.1077835

Dror, I. E. (2007). Perception of risk and the decision to use force. Policing: A Journal of Policy and Practice, 1, $265-272$. doi:10.1093/police/pam041

Evans, J. S. (2008). Dual-processing accounts of reasoning, judgment, and social cognition. Annual Review of Psychology, 59, 255-278. doi:10.1146/annurev.psych.59.103006.093629 
Everly, G. S., \& Lating, J. M. (2013). The anatomy and physiology of the human stress response. In G. S. Everly Jr. and J. M. Lating (Eds.), A clinical guide to the treatment of the human stress response (pp. 17-51). New York, NY: Springer.

Ferdik, F. V., Kaminski, R. J., Cooney, M. D., \& Sevigny, E. L. (2014). The influence of agency policies on conducted energy device use and police use of lethal force. Police Quarterly, 17, 328-358. doi:10.1177/1098611114548098

Fradella, H., Morrow, W., \& White, M. (2016). Terry and SQF viewed through the lens of the suspicion heuristic. Criminal Law Bulletin, 52, 871-922. doi:10.2139/ssrn.2749229

Fyfe, J. J. (1979). Administrative interventions on police shooting discretion: An empirical examination. Journal of Criminal Justice, 7, 309-323.

Fyfe, J. J. (1981). Who shoots? A look at officer race and police shooting. Journal of Police Science and Administration, 9 , 367-382.

Fyfe, J. J. (1982). Blind justice: Police shootings in Memphis. Journal of Criminal Law \& Criminology, 73, 707-722.

Fyfe,J.J.(1988).Policeuse ofdeadly force:Researchandreform.Justice Quarterly, 5, 165-205.doi:10.1080/07418828800089691

Fyfe, J. J. (2015). The split-second syndrome and other determinants of police violence. In R. G. Dunham \& G. P. Alpert (Eds.), Critical issues in policing: Contemporary readings (7th ed., pp. 451-467). Long Grove, IL: Waveland Press.

Greitzer, F. L., Podmore, R., Robinson, M., \& Ey, P. (2010). Naturalistic decision making for power system operators. International Journal of Human-Computer Interaction, 26, 278-291. doi:10.1080/10447310903499070

Hammond, K. R. (1993). Naturalistic decision making from a Brunskikian viewpoint: Its past, present, future. In G. A. Klein, J. Orasanu, R. Calderwood, \& C. E. Zsambok (Eds.), Decision making in action: Models and methods (pp. 205-227). Norwood, NJ: Ablex.

Hine, K. A., Porter, L. E., Westera, N. J., \& Alpert, G. P. (2016). Too much or too little? Individual and situational predictors of police force relative to suspect resistance. Policing and Society: An International Journal of Research and Policing, 28, 587-604. doi:10.1080/10439463.2016.1232257

Hine, K. A., Porter, L. E., Westera, N. J., Alpert, G. P., \& Allen, A. (2018). What were they thinking? Factors influencing police recruits' decisions about force. Policing and Society: An International Journal of Research and Policing. Advance online publication. doi:10.1080/10439463.2018.1432612

Hunt, R. G., Krzystofiak, F. J., Meindl, J. R., \& Yousry, A. M. (1989). Cognitive style and decision making. Organizational Behavior and Human Decision Processes, 44, 436-453. doi:10.1016/0749-5978(89)90018-6

International Association of Chiefs of Police. (2017). National consensus policy and discussion paper on use of force. Retrieved from http://www.theiacp.org/Portals/0/documents/pdfs/National_Consensus_Policy_On_Use_Of_Force.pdf

James, L., James, S. M., \& Vila, B. J. (2016). The reverse racism effect: Are cops more hesitant to shoot Black than White suspects? Criminology \& Public Policy, 15, 457-479. doi:10.1111/1745-9133.12187

James, L., Klinger, D., \& Vila, B. (2014). Racial and ethnic bias in decisions to shoot seen through a stronger lens: experimental results from high-fidelity laboratory simulations. Journal of Experimental Criminology, 10, 323-340. doi:10.1007/ s11292-014-9204-9

James, L., Vila, B., \& Daratha, K. (2012). Results from experimental trials testing participant responses to White, Hispanic and Black suspects in high-fidelity deadly force judgment and decision-making simulations. Journal of Experimental Criminology, 9, 189-212. doi:10.1007/s11292-012-9163-y

Johnson, B. (2008). Crucial elements of police firearms training: Refine your firearms skills, training and effectiveness. New York, NY: Looseleaf Law.

Johnson, R. R. (2009). Explaining patrol officer drug arrest activity through expectancy theory. Policing: An International Journal of Police Strategies \& Management, 32, 6-20. doi:10.1108/13639510910937085

Johnson, R. R. (2013). Arrest as displaced aggression. Criminal Justice and Behavior, 40, 1149-1162. doi:10.1177/0093854813484132

Kaempf, G. L., Orasanu, J., Zsambok, C., \& Klein, G. (1997). Current and future applications of naturalistic decision making in aviation. In C. E. Zsambok \& G. Klein (Eds.), Naturalistic decision making (pp. 81-90). Mahwah, NJ: Lawrence Erlbaum.

Kahneman, D., \& Lovallo, D. (1993). Timid choices and bold forecasts: A cognitive perspective on risk taking. Management Science, 39, 17-31.

Kenneth, R. H. (2010). Intuition, no! . . . Quasirationality, yes. Psychological Inquiry, 21, 327-337. doi:10.1080/10478 40X.2010.521483

Klein, G. (2008). Naturalistic decision making. Human Factors: The Journal of the Human Factors and Ergonomics Society, 50, 456-460. doi:10.1518/001872008X288385

Klein, G. (2015). A naturalistic decision making perspective on studying intuitive decision making. Journal of Applied Research in Memory and Cognition, 4, 164-168.

Klein, G. A. (1993). A Recognition-Primed Decision (RPD) model of rapid decision making. In G. A. Klein, J. Orasanu, R. Calderwood, \& C. E. Zsambok (Eds.), Decision making in action: Models and methods (pp. 138-147). Norwood, NJ: Ablex.

Klinger, D. A. (2004). Into the kill zone: A cop's eye view of deadly force. San Francisco, CA: Jossey-Bass. 
Kruglanski, A. W., \& Orehek, E. (2007). Partitioning the domain of social inference: Dual mode and systems models and their alternatives. Annual Review of Psyhcology, 58, 291-316. doi:10.1146/annurev.psych.58.110405.085629

Livingston, J. A. (2003). Metacognition: An overview. Retrieved from http://gse.buffalo.edu/fas/shuell/cep564/metacog.htm

Mitchell, L., \& Flin, R. (2007). Shooting decisions by police firearms officers. Journal of Cognitive Engineering and Decision Making, 1, 375-390. doi:10.1518/155534307X264861

Orasanu, J., \& Connolly, T. (1993). The reinvention of decision making. In G. A. Klein, J. Orasanu, R. Calderwood, \& C. E. Zsambok (Eds.), Decision making in action: Models and methods (pp. 3-20). Norwood, NJ: Ablex.

Phillips, S. W., \& Sobol, J. J. (2012). Police decision making: An examination of conflicting theories. Policing: An International Journal of Police Strategies \& Management, 35, 551-565. doi:10.1108/13639511211250794

Police Executive Research Forum. (2016). Critical Issues in Policing Series: Guiding principles on use of force. Washington, DC: Author.

Polis Solutions. (2018). T3 training: Tact, tactics, and trust. Retrieved from https://www.polis-solutions.net/t3

Queensland Police Service. (2016). Operational procedures manual. Brisbane: Queensland Government. Retrieved from https://www.police.qld.gov.au/corporatedocs/OperationalPolicies/opm.htm

Rajakaruna, N., Henry, P. J., Cutler, A., \& Fairman, G. (2017). Ensuring the validity of police use of force training. Police Practice and Research, 18, 507-521. doi:10.1080/15614263.2016.1268959

Renden, P. (2015). Police performance under pressure: Arrest and self-defence skills. Amsterdam, The Netherlands: Department of Movement and Behavioral Sciences, Free University of Amsterdam.

Sinclair, M. (2010). Misconceptions about intuition. Psychological Inquiry, 21, 378-386. doi:10.1080/1047840X.2010.523874

Smith, M. R., \& Alpert, G. P. (2007). Explaining police bias: A theory of social conditioning and illusory correlation. Criminal Justice and Behavior, 34, 1262-1283. doi:10.1177/0093854807304484

Stenning, P., Birkbeck, C., Adang, O., Baker, D., Feltes, T., Gabaldon, L. G., . . Waddington, P. A. J. (2009). Researching the use of force: The background to the international project. Crime, Law and Social Change, 52, 95-110. doi:10.1007/ s10611-008-9177-6

Sykes, R. E., \& Brent, E. E. (1983). Policing: A social behaviorist perspective. New Brunswick, NJ: Rutgers University Press.

Terrill, W. (2003). Police use of force and suspect resistance: The micro process of the police-suspect encounter. Police Quarterly, 6, 51-83. doi:10.1177/1098611102250584

Terrill, W. (2005). Police use of force: A transactional approach. Justice Quarterly, 22, $107-138$. doi:10.1080/0741882042000333663

Terrill, W., \& Mastrofski, S. (2002). Situational and officer-based determinants of police coercion. Justice Quarterly, 19, 251-248. doi:10.1080/07418820200095221

Terrill, W., \& Paoline, E. A., III. (2017). Police use of less lethal force: Does administrative policy matter? Justice Quarterly, 34, 193-216. doi:10.1080/07418825.2016.1147593

Toch, H. (1996). The violence-prone police officer. In W. A. Geller \& H. Toch (Eds.), Police violence: Understanding and controlling police abuse of force (pp. 94-112). London, England: Yale University Press.

Wang, Y., Highhouse, S., Lake, C. J., Petersen, N. L., \& Rada, T. B. (2015). Meta-analytic investigations of the relation between intuition and analysis. Journal of Behavioral Decision Making, 30, 15-25. doi:10.1002/bdm.1903

White, M. D. (2001). Controlling police decisions to use deadly force: Reexamining the importance of administrative policy. Crime \& Delinquency, 47, 131-151. doi:10.1177/0011128701047001006

White, M. D., \& Fradella, H. F. (2016). Stop and frisk: The use and abuse of a controversial policing tactic. New York: New York University Press.

Yeoman, B. (2017, June 14). Mindful policing: The future of force. Mindful: Healthy mind, healthy life. Available from https://www.mindful.org

Zsambok, C. E., \& Klein, G. (1997). Naturalistic decision making. Mahwah, NJ: Lawrence Erlbaum.

Kelly A. Hine is a lecturer at the Australian National University and a researcher with the ANU Centre for Social Research $\&$ Methods. Her research centers on police-citizen interactions, including the use of force by police and officer injuries. Her research examines the decision-making process, and impediments to this process, during situations that are typically dynamic and volatile. In addition to her research interest in frontline policing, her areas of expertise include police misconduct and police integrity.

Louise E. Porter is a senior lecturer in the School of Criminology and Criminal Justice at Griffith University, Australia, and member of the Griffith Criminology Institute. Her research on policing focuses on police misconduct and use of force, as well as police oversight and integrity management.

Nina J. Westera was a lecturer in the School of Criminology and Criminal Justice at Griffith University, Australia, and was a member of the Griffith Criminology Institute. Her expertise focused on investigative interviewing, especially complainants of sexual and violent offending, and the use of police interviews as video evidence. An influential researcher and valued colleague, she passed away in May 2017. 
Geoffrey P. Alpert is a professor of criminology and criminal justice at the University of South Carolina and holds an appointment at Griffith University. He is also a chief research advisor for National Institute of Justice (NIJ). For the past 30 years, his research interests have included police use of force, emergency driving, and the linkages between researchers and practitioners.

Andrea Allen is associate professor of criminal justice at Clayton State University. Her research focuses on policing and is published in outlets such as Crime \& Delinquency, Journal of Quantitative Criminology, Police Quarterly, and Policing. 